\title{
Radix Sophorae Flavescentis inhibits proliferation and induces apoptosis of AGS human gastric cancer cells
}

\author{
JI SUN KIM ${ }^{1}$, SEUNG JAE SHIN ${ }^{1}$, JUNG NAM KIM ${ }^{1}$, MIN JI KWON ${ }^{1}$, EUN YEONG LIM ${ }^{2}$, \\ YUN TAI KIM ${ }^{2}$, HYUNGWOO KIM ${ }^{3}$ and BYUNG JOO KIM ${ }^{1}$
}

\begin{abstract}
${ }^{1}$ Division of Longevity and Biofunctional Medicine, Pusan National University School of Korean Medicine, Yangsan, Gyeongosangnam-do 50612; ${ }^{2}$ Research Group of Innovative Special Food, Korea Food Research Institute, Wanju, North Jeolla 55365; ${ }^{3}$ Division of Pharmacology, Pusan National University School of Korean Medicine, Yangsan, Gyeongosangnam-do 50612, Republic of Korea
\end{abstract}

Received August 16, 2018; Accepted December 13, 2018

DOI: $10.3892 / \mathrm{mmr} .2018 .9776$

\begin{abstract}
Traditional herbal medicines are being increasingly used worldwide to treat cancer. Radix Sophorae Flavescentis (RSF) is a Chinese herb, which has numerous pharmacological properties, including anti-tumour effects. In this study, we investigated the mechanisms underlying RSF-induced apoptosis in human gastric cancer cells (AGS cells). We found that RSF treatment $(20-200 \mu \mathrm{g} / \mathrm{ml})$ inhibited the proliferation of AGS cells and increased the sub-G1 phase ratio. RSF-induced cell death was associated with the downregulation of $\mathrm{BCl}-2$ and upregulation of $\mathrm{Bax}$. In addition to increasing the expression levels of apoptosis-mediating surface antigen FAS and Fas ligand, RSF also activated caspase-3; however, mitogen-activated protein kinase appeared to inhibit RSF-induced cell death. RSF also led to an increased production of reactive oxygen species. Based on these results, we propose that RSF could be a potential therapeutic agent for gastric cancer.
\end{abstract}

\section{Introduction}

Gastric cancers that develop from the lining of the stomach are highly aggressive. Currently, gastric cancers are the second leading cause of cancer-related deaths worldwide (1-3), and development of novel therapeutic options is urgently required (3).

Traditional herbal medicines have become increasingly popular among cancer patients $(4,5)$, mainly because of minimal complications and side-effects from treatment and

Correspondence to: Professor Byung Joo Kim, Division of Longevity and Biofunctional Medicine, Pusan National University School of Korean Medicine, 49 Busandaehakro, Yangsan Gyeongosangnam-do 50612, Republic of Korea

E-mail: vision@pusan.ac.kr

Key words: Radix Sophorae Flavescentis, apoptosis, gastric cancer, AGS improved quality of life (5-7). Radix Sophorae Flavescentis (RSF) is an ancient Chinese herb (8) that contains active ingredients such as sophordine, matrine, and sophocarpine $(8,9)$. RSF has detoxification, diuretic, and insect repellent properties (10). It is also one of the important ingredients for the treatment of contact dermatitis and local pruritus of the vagina $(11,12)$. It also has other pharmacological properties, such as antibacterial, anti-tumour, and anti-viral (against hepatitis B virus) effects (12-14). RSF induces apoptosis of laryngeal neoplasm Hep2 cells (15), esophageal carcinoma TE- 8 cells (10), and PC-3 prostate cancer cells (16). However, evidence is minimal in order to recommend RSF for use in the treatment of gastric cancers. Therefore, we investigated the mechanisms underlying apoptosis induced by RSF in AGS cells to improve our understanding and also expand the scope of its therapeutic applications.

\section{Materials and methods}

Preparation of RSF. Radix Sophorae extract was purchased from the Korea Plant Extract Bank (Ochang, Chungbuk, Korea). Following the supplier instructions, Radix Sophorae was extracted in $95 \%$ ethyl alcohol at $45^{\circ} \mathrm{C}$ for 3 days. The extracted solution was filtered and evaporated at $45^{\circ} \mathrm{C}$. The dried extract was dissolved in methanol and diluted in water to obtain a final concentration $2 \mathrm{mg} / \mathrm{ml}$. Matrine and oxymatrine (Sigma-Aldrich; Merck KGaA, Darmstadt, Germany) were dissolved in methanol and diluted in water to obtain solutions with final concentrations of 100, 200,300, 400 and $500 \mu \mathrm{g} / \mathrm{ml}$. Solutions of Radix Sophorae, matrine, and oxymatrine were filtered through a $0.45 \mu \mathrm{m}$ regenerated cellulose membrane filter (Sartorius AG, Goettingen, Germany). Analytical high-performance liquid chromatography (HPLC) was performed in a JASCO HPLC system (JASCO, Hachioji, Tokyo, Japan) comprising a PU-980 pump, and an AS-950-10 autosampler equipped with MD-2010 Plus multi-wavelength detector. The chromatographic separation was performed with a Waters Symmetry ${ }^{\circledR}$ C18 $(4.6 \times 250 \mathrm{~mm}$, particle size $5 \mu \mathrm{m})$ column. The ultraviolet (UV) detection was set at $220 \mathrm{~nm}$. A reverse-phase HPLC assay was performed using an isocratic system with methanol:water containing $3 \%$ phosphoric acid 
$(4: 96 \mathrm{v} / \mathrm{v})$ as the mobile phase for a $30 \mathrm{~min}$ run. The flow rate was set to $1 \mathrm{ml} / \mathrm{min}$ and the column was maintained at $30^{\circ} \mathrm{C}$. Similar to the previous HPLC run, the UV detection was set at $220 \mathrm{~nm}$. The injection volume was $10 \mu \mathrm{l}$. The standard calibration curve of matrine and oxymatrine showed linearity $\left(\mathrm{r}^{2}>0.999^{* *}\right)$ in the range of $100-500 \mu \mathrm{g} / \mathrm{ml}$. Quantitative analysis was repeated three times, and all data are expressed as mean \pm standard deviation. The concentrations of matrine and oxymatrine were determined to be $70.47 \pm 1.27$ and $299.87 \pm 3.746 \mathrm{mg} / \mathrm{g}$, respectively.

Cell culture and reagents. The AGS human gastric adenocarcinoma cell line was used for the experiments. These cells were propagated in RPMI-1640 medium (Gibco; Thermo Fisher Scientific, Inc., Waltham, MA, USA) supplemented with $10 \%$ heat-inactivated fetal bovine serum (Invitrogen; Thermo Fisher Scientific, Inc.) and 1\% antibiotic mix (penicillin and streptomycin) (Invitrogen; Thermo Fisher Scientific, Inc.) at $37^{\circ} \mathrm{C}$. SP600125 and PD98059 were purchased from Tocris (Bristol, UK). All other reagents were obtained from Sigma-Aldrich (Merck KGaA).

Cell viability assay. Cell viability was studied using the MTT [3-(4,5-dimethylthiazol-2-yl)-2,5-diphenyltetrazolium bromide] assay. AGS cells were treated with MTT solution and incubated for $2 \mathrm{~h}$ at $37^{\circ} \mathrm{C}$, following which, absorbance was measured at $570 \mathrm{~nm}$.

Cell-cycle analysis. To AGS cells, ethyl alcohol was added and the cells vortexed prior to overnight incubation at $4^{\circ} \mathrm{C}$. Samples were centrifuged for $5 \mathrm{~min}$ and the supernatant was discarded. Cell pellets were resuspended in propidium iodine (PI) staining solution $(5 \mathrm{mg} / \mathrm{ml} ; 2 \mu \mathrm{l})$ containing RNase (2 $\mu \mathrm{l})(17,18)$ and centrifuged at $20,000 \mathrm{x} \mathrm{g}$ for $10 \mathrm{sec}$. After incubation at room temperature for $40 \mathrm{~min}$ in the dark, the samples were analysed using a fluorescence-activated cell sorter (FACScan; Becton-Dickinson, Mountain View, CA, USA) set at $\lambda=488 \mathrm{~nm}$ and using the Cell-Quest software (Becton-Dickinson, Franklin Lakes, NJ, USA).

Western blotting. Total cell extract was prepared using RIPA buffer (Cell Signaling Technology Inc., Danvers, MA) containing $1 \mathrm{mM}$ phenylmethylsulfonyl fluoride (PMSF). Protein content was measured using the Bradford method (Bio-Rad Laboratories, Hercules, CA). Equal amounts of proteins were fractionated by SDS-PAGE and transferred to a PVDF membrane (Bio-Rad Laboratories, Hercules, CA). Membranes were blocked for at least $1 \mathrm{~h}$ with $5 \%$ non-fat dry milk prior to incubating overnight with antibodies against Bcl-2 (cat. no. SC-783; Santa Cruz Biotechnology, Dallas, TX, USA), Bax (cat. no. SC-493; Santa Cruz Biotechnology), JNK (cat. no. \#9252; Cell Signaling Technology, Beverly, MA, USA), p-JNK (cat. no. \#9255; Cell Signaling Technology), p38 MAPK (cat. no. \#9228; Cell Signaling Technology), p-p38 MAPK (cat. no. \#9211; Cell Signaling Technology, Beverly, MA, USA) and $\beta$-actin (cat. no. SC-47778; Santa Cruz Biotechnology) at $4^{\circ} \mathrm{C}$. The membrane was further incubated with secondary antibodies conjugated to HRP at room temperature for $1 \mathrm{~h}$. Bands of interest were visualised by chemiluminescence (Super Signal West Femto; Thermo Fisher
Scientific, Inc.). Secondary horseradish peroxidase-conjugated antibodies, including goat anti-rabbit IgG (cat. no. sc-2004; Santa Cruz Biotechnology) and goat anti-mouse IgG (cat. no. SC-2005; Santa Cruz Biotechnology), were used. Relative intensities of protein (BCl-2 and $\mathrm{Bax}$ ) bands were analyzed with a GS-710 Image Densitometer (Bio-Rad Laboratories, Hercules, CA, USA).

Reverse transcription-polymerase chain reaction (PCR). Total RNA was isolated using TRIzol Reagent (Invitrogen; Thermo Fisher Scientific, Inc.), and converted to cDNA using AccuPower RT-PreMix (Bioneer Co., Daejeon, Korea). Specific DNA sequences were amplified using AccuPower PCR-PreMix (Bioneer Co.). PCR primers used in this study are: Fas 5'-ATGCTGGGCATCTGGACCCTCCTA-3' forward and 5'-TCTGCACTTGGTATTCTGGGTCCG-3' reverse; FasL 5'-ACTTCCGGGGTCAATCTTGC-3' forward and 5'-TAGAACATCTCGGTGCCTGTA-3' reverse; and $\beta$-actin 5'-CAAGAGATGGCCACGGCTGCT-3' forward and 5'-TCC TTCTGCATCCTGTCGGCA-3' reverse. Amplified products were analysed in $1 \%$ agarose gel, and images were captured using the GelDoc-It TS Imaging System (UVP, Upland, CA, USA).

Caspase assay. Caspase-3 assay kits (Cellular Activity Assay Kit Plus; BioMol Plymouth, PA, USA) were used. After resuspending the cells in ice-cold cell lysis buffer, the supernatant was removed. Supernatant samples were incubated with caspase substrate (400-1M Ac-DEVD-pNA; $50 \mu \mathrm{l})$ at $37^{\circ} \mathrm{C}$. Each sample was read at $405 \mathrm{~nm}$ at several time-points.

Measurement of ROS production. ROS generation in AGS cells was quantified using DCF-DA (2', 7'-dichlorodihydrofluorescein diacetate; Molecular Probes, Eugene, OR, USA). The cells were treated with $20 \mu \mathrm{l}$ DCF-DA at $37^{\circ} \mathrm{C}$ for $30 \mathrm{~min}$ and washed with PBS. Fluorescence was measured using an FACS system (Becton-Dickinson, Mountain View, CA, USA), and at excitation/emission wavelength of 488/525 nm.

Statistical analysis. Results are expressed as the mean \pm standard error of the mean. $\mathrm{N}$ values refer to the number of cells used in the experiments. One-way analysis of varaicne with Tukey's post hoc comparison was used for multiple comparisons. Statistical analysis was performed using Prism 6.0 (GraphPad Software, Inc., La Jolla, CA, USA) and Origin 8.0 (OriginLab Corporation, Northampton, MA, USA) software programs. $\mathrm{P}<0.05$ was considered to indicate a statistically significant difference.

\section{Results}

Identification of standard components of RSF. Matrine and oxymatrine were identified based on the HPLC chromatogram of RSF with retention times of 11.6 and $25.7 \mathrm{~min}$, respectively (Fig. 1).

Apoptosis by RSF in AGS cells. To determine whether RSF suppresses AGS cell growth, MTT assays were performed after culturing cells with different concentrations of RSF for $24 \mathrm{~h}$. Cell viability decreased remarkably following RSF 


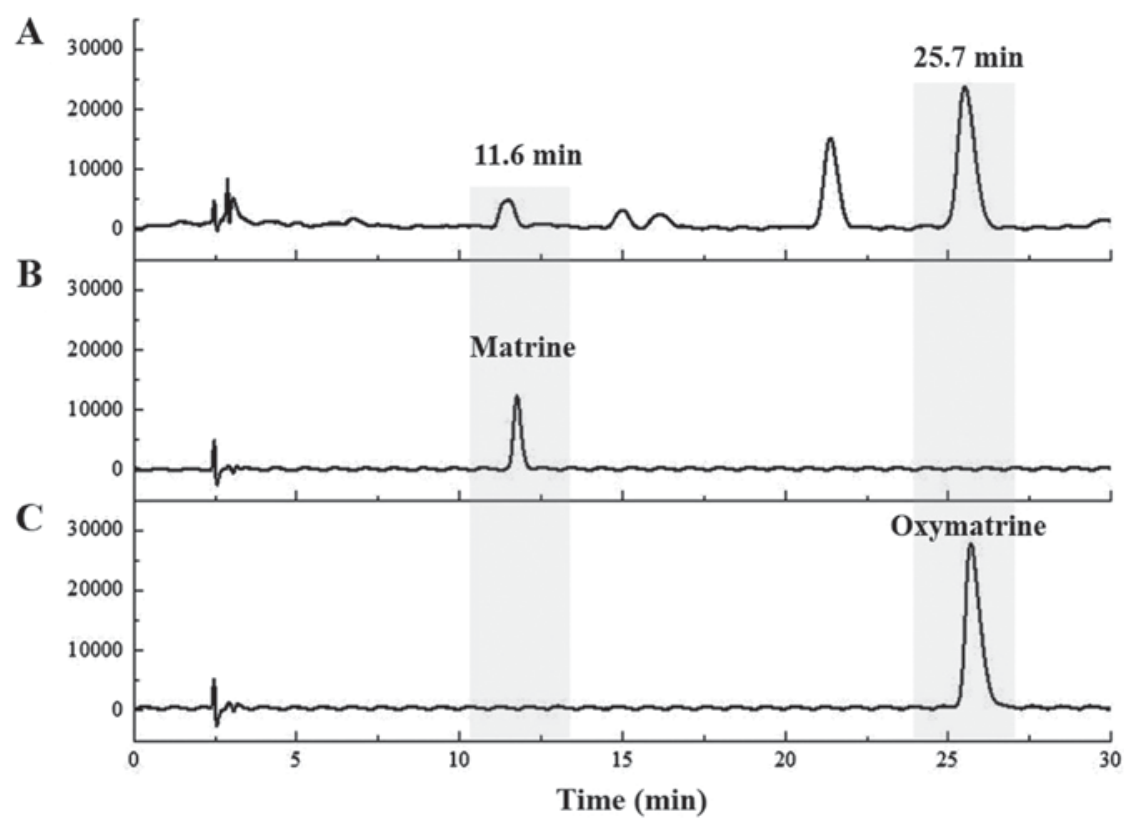

Figure 1. Presence of matrine and oxymatrine in Radix Sophorae Flavescentis extract was established by high-performance liquid chromatography and their levels were quantified using calibration curves obtained with purchased standards. High-performance liquid chromatograms of (A) Radix Sophorae Flavescentis extract and standard compounds (B) Matrine and (C) Oxymatrine detected at a wavelength of $220 \mathrm{~nm}$.
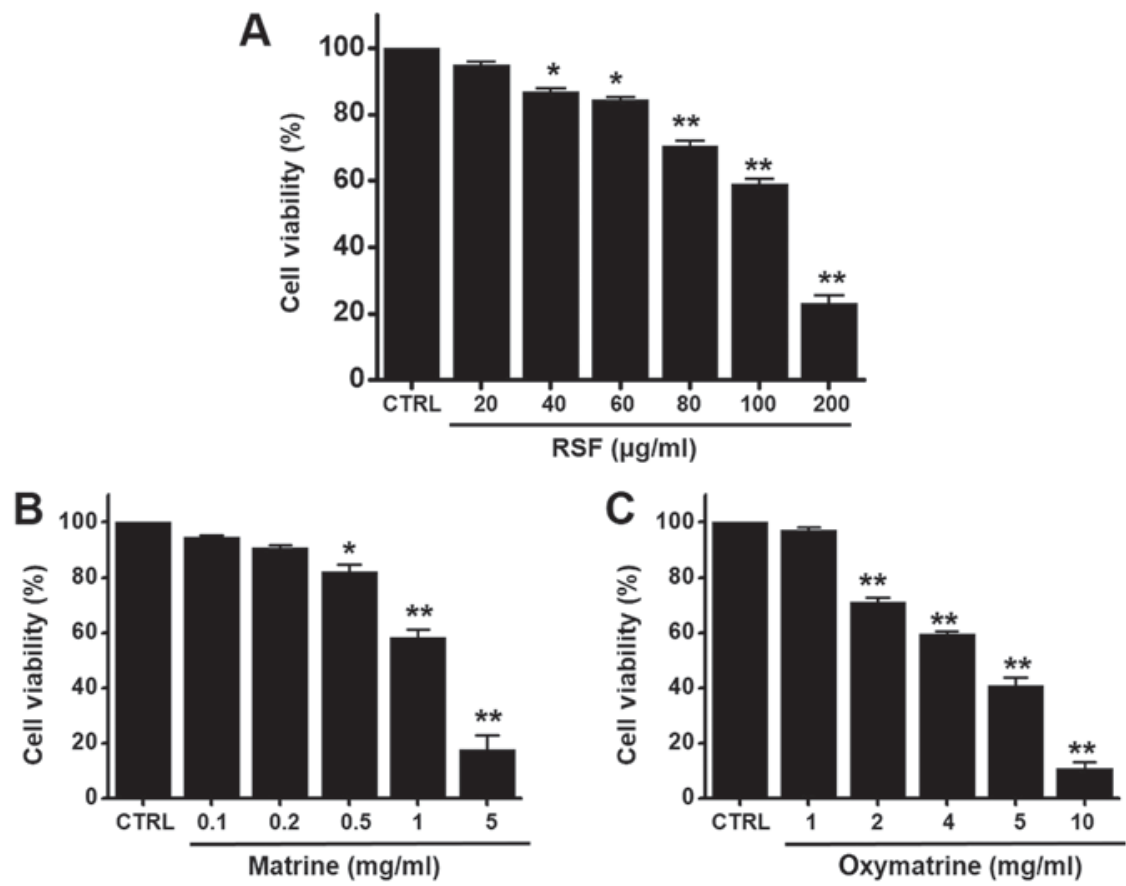

Figure 2. RSF inhibits the cell viability in AGS cells. Cell viability was determined by MTT assay. (A) RSF reduced cell viability in a dose-dependent manner, over a $24 \mathrm{~h}$ period. Number of viable cells following treatment with RSF are expressed as percentages of untreated cells. (B) Matrine reduced cell viability in a dose-dependent manner. (C) Oxymatrine additionally reduced cell viability in a dose-dependent manner. Results are presented as the mean \pm standard error of the mean. ${ }^{*} \mathrm{P}<0.05,{ }^{* *} \mathrm{P}<0.01$ vs. untreated cells. RSF, Radix Sophorae Flavescentis; CTRL, control.

treatment. Culturing in the presence of RSF concentrations of $20,40,60,80,100$, or $200 \mu \mathrm{g} / \mathrm{ml}$ inhibited AGS survival by $94.9 \pm 1.1,86.8 \pm 1.3,84.4 \pm 0.9,70.6 \pm 1.5,59.0 \pm 1.6$, or $23.2 \pm 2.5$, respectively, as determined by MTT assay ( $n=6$; Fig. 2A). In addition, we investigated the effects of matrine and oxymatrine, the major ingredients in RSF, on cell viability by using the MTT assay. The presence of matrine $(0.1,0.2$, $0.5,1$, or $5 \mathrm{mg} / \mathrm{ml})$ or oxymatrine $(1,2,4,5$, or $10 \mathrm{mg} / \mathrm{ml})$ inhibited the survival of AGS cells ( $n=5$; Fig. 2B and C). To determine whether RSF induces apoptosis, cell cycle was studied by using flow cytometry. Cells were treated with RSF for $24 \mathrm{~h}$ (with concentrations ranging from 20 to $200 \mu \mathrm{g} / \mathrm{ml}$; Fig. 3). The sub-G1 phase ratio was found to be increased by RSF by $4.8 \pm 0.1$ at $20 \mu \mathrm{g} / \mathrm{ml}, 5.6 \pm 1.0$ at $40 \mu \mathrm{g} / \mathrm{ml}, 8.8 \pm 3.0$ at $60 \mu \mathrm{g} / \mathrm{ml}, 9.0 \pm 1.3$ at $80 \mu \mathrm{g} / \mathrm{ml}, 12.1 \pm 1.9$ at $100 \mu \mathrm{g} / \mathrm{ml}$, and $22.3 \pm 7.2 \%$ at $200 \mu \mathrm{g} / \mathrm{ml}$ compared to that of the untreated 
A
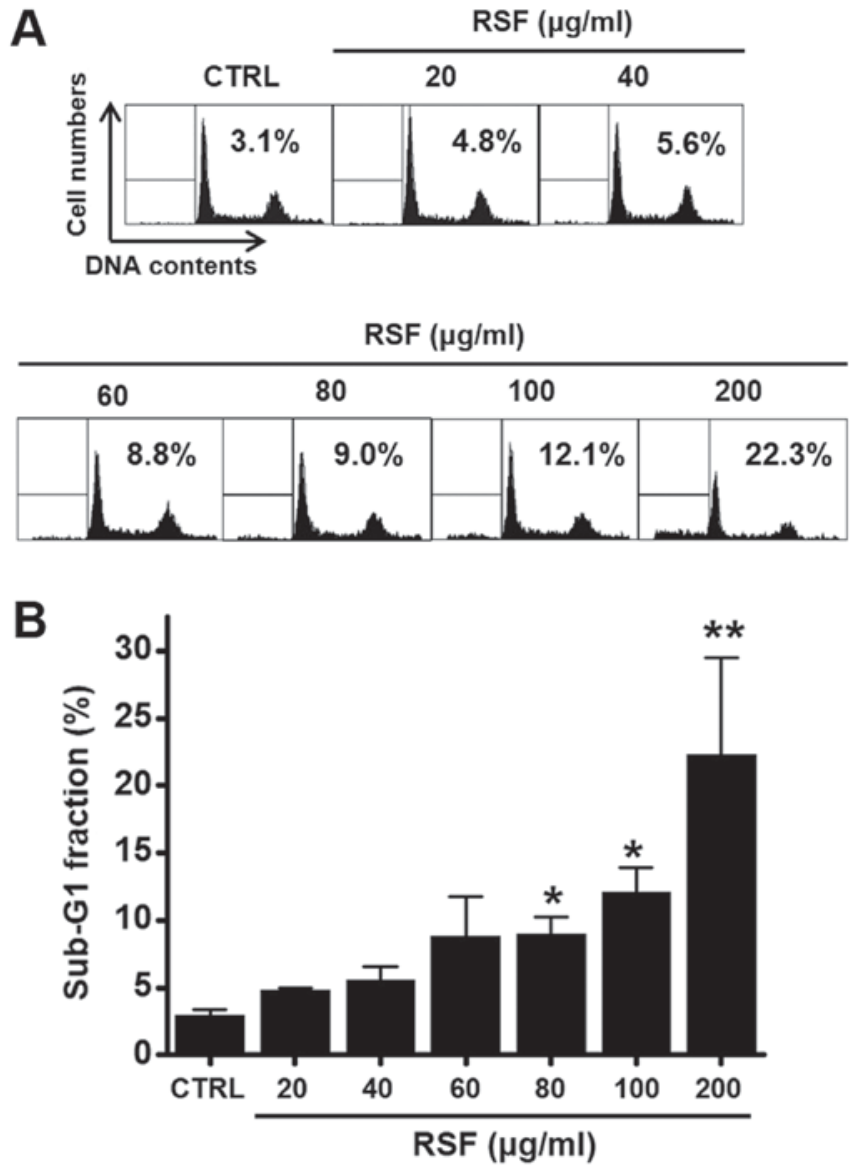

Figure 3. Induction of apoptosis in AGS cells by RSF. (A) Cells were treated with RSF for $24 \mathrm{~h}$ (at concentrations between 20 and $200 \mu \mathrm{g} / \mathrm{ml}$ ). Cell cycle analysis was conducted by flow cytometry. (B) Sub-G1 fractions were significantly and dose-dependently increased by RSF. Results are presented as the mean \pm standard error of the mean. ${ }^{*} \mathrm{P}<0.05,{ }^{* *} \mathrm{P}<0.01$ vs. untreated cells. RSF, Radix Sophorae Flavescentis; CTRL, control.

cells ( $n=6$, respectively; Fig. 3A and B). These results suggest that RSF has anti-cancer effects and these effects are linked to apoptosis.

Mitochondria- and caspase-dependent pathways in AGS cells. To determine whether RSF-induced apoptosis in AGS cells is regulated by Bcl-2 (anti-apoptotic) and Bax (pro-apoptotic), we performed western blotting after exposing the cells to various concentrations of RSF (ranging from 20 to $200 \mu \mathrm{g} / \mathrm{ml}$ ). While Bcl-2 expression was inhibited by RSF, Bax was upregulated (Fig. 4A). Also, the Fas/FasL system, a key player in the death receptor-mediated apoptosis, was examined. Fas and FasL expression levels were both up-regulated by RSF (Fig. 4B). Caspase assays were performed to assess the activity of caspase- 3 in the AGS cells. Caspase activity increased after treatment with RSF (concentration ranging from 20 to $200 \mu \mathrm{g} / \mathrm{ml}$ ), and that these activities were suppressed by zVAD-fmk (Fig. 4C). These results suggest that RSF-induced apoptosis is mediated by a mitochondrial- and caspase-dependent pathway in AGS cells.

c-Jun N-terminal kinase (JNK) and mitogen-activated protein kinase (MAPK) pathways in AGS cells. To investigate the involvement of MAPK pathways in the inhibition of AGS cell proliferation by RSF, cell viability was measured after treating the cells with different concentrations (from 20 to $200 \mu \mathrm{g} / \mathrm{ml}$ ) of RSF, with or without the JNK inhibitor or MAPK inhibitor (SP600125 or PD98059) using the MTT assay. Co-treatment notably inhibited RSF-induced cell death when cells were co-treated with $200 \mu \mathrm{g} / \mathrm{ml}$ of RSF. Co-treatment with RSF (20, $40,60,80,100$, or $200 \mu \mathrm{g} / \mathrm{ml}$ ) and SP600125, inhibited cell survival by $98.3 \pm 1.6,92.6 \pm 3.1,87.0 \pm 2.1,88.9 \pm 2.1,82.7 \pm 3.0$, and $67.6 \pm 1.6 \%$, respectively, also determined by the MTT assay (n=6; Fig. 5A). Co-treatment with RSF (20, 40, 60, 80, 100 or $200 \mu \mathrm{g} / \mathrm{ml}$ ) and PD98059 also inhibited cell survival, but by $96.2 \pm 2.1,94.3 \pm 1.2,87.6 \pm 2.0,76.4 \pm 1.9,69.5 \pm 2.1$, and $46.3 \pm 1.7 \%$, respectively ( $n=6$; Fig. $5 \mathrm{~B}$ ). The expression of proteins corresponding to JNK, p-JNK, p38 MAPK and p-p38 MAPK was observed using western blotting analysis. The expression of p-JNK and p-p38 MAPK protein increased with RSF addition (Fig. 5C). These results suggest that both JNK and MAPK are involved in the RSF-induced apoptosis of AGS cells.

Intracellular reactive oxygen species (ROS) pathway in AGS cells. As ROS plays a key role in apoptosis, we studied whether RSF can generate ROS in AGS cells. To check whether ROS generation was associated with RSF-induced apoptosis, ROS was investigated using a fluorescent dye, DCF-DA. As indicated in Fig. 6A, when the cells were exposed to RSF, ROS levels increased. Flow cytometry indicated that ROS generation significantly increased in a dose-dependent manner (RSF from 20 to $200 \mu \mathrm{g} / \mathrm{ml}$ ) (Fig. 6B).

\section{Discussion}

RSF is extracted from the dried root of Sophora Flavescens Ait, and it contains alkaloids including matrine and oxymatrine that form its key constituents $(15,19)$. Modern pharmacological experiments show that RSF has a variety of pharmacological properties. It is commonly used for the treatment of viral hepatitis, cancer, viral myocarditis, and skin diseases $(20,21)$. The main components of RSF are alkaloids, flavonoids, alkylxanthones, quinones, and triterpene glycosides (20-22). Matrine and oxymatrine are the two major alkaloids found in the roots of Sophora sp. (21). They inhibit the growth of various tumour cell lines (21-24). Matrine inhibits the invasiveness and metastasis of various tumour cells, such as A375, HeLa, and K-562 (25,26). Oxymatrine has anti-cancer effects against human gastric, breast, and pancreatic cancer cells (27-29). Although, many reports suggest that RSF inhibits the proliferation of several cancer cell lines (23-29), its anti-cancer activity in human gastric adenocarcinoma AGS cells remains unclear. Therefore, we examined the mechanism behind this phenomenon, and found that RSF induces apoptotic signalling via mitochondrial- and caspase-dependent pathways mediated by ROS generation in the human gastric cancer cells.

In the present study, AGS cell viability decreased remarkably following RSF treatment (Fig. 2A). Also, matrine (Fig. 2B) or oxymatrine (Fig. 2C) inhibited the survival of AGS cells. RSF is used in traditional Chinese medicine to treat various diseases, and has the ability to clear heat and dampness from the body $(20,21)$. Matrine or oxymatrine is one of the major bioactive compounds extracted from RSF (21). 
A a

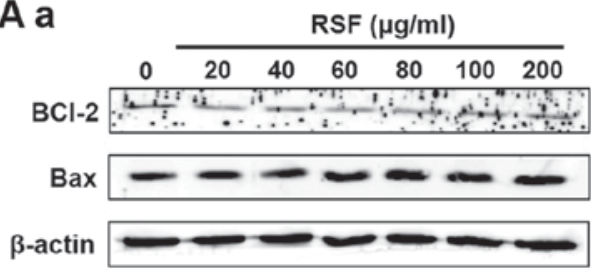

B

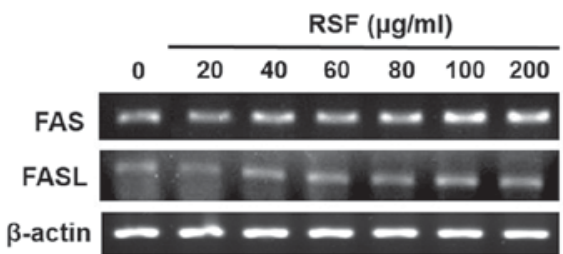

b
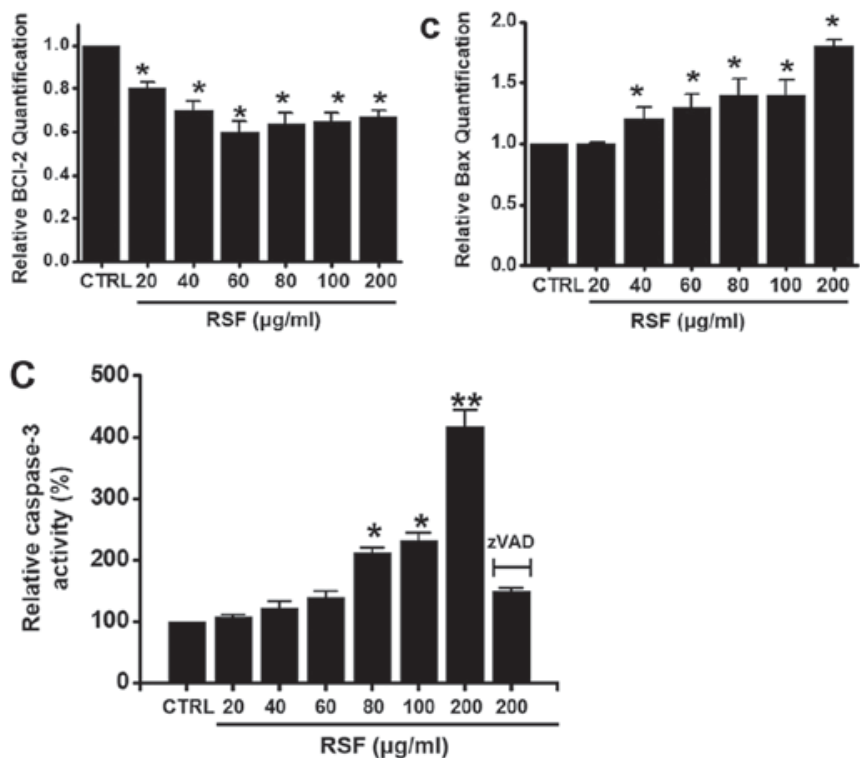

Figure 4. Bcl-2, Bax protein regulation and caspase-3 activities are shown in AGS cells after treatment with RSF. (Aa) Western blotting was performed on AGS cells treated with different RSF concentrations for $24 \mathrm{~h}$. Bcl-2 expression was downregulated by RSF, whereas, Bax expression was upregulated. Each level of (Ab) Bcl-2 or (Ac) Bax protein expression was normalized to that of the corresponding $\beta$-actin, and the mean values are presented as bar graphs. (B) Reverse transcription-polymerase chain reaction was performed on AGS cells treated with different RSF concentrations for $24 \mathrm{~h}$. The Fas and FasL expression levels were upregulated by RSF. (C) Caspase assays were performed following the addition of the indicated RSF concentration for $24 \mathrm{~h}$ to the culture cells. Cells were treated with zVAD-fm as a pan-caspase inhibitor. $\beta$-actin was used as the loading control. Results are presented as the mean \pm standard error of the mean. ${ }^{*} \mathrm{P}<0.05,{ }^{* *} \mathrm{P}<0.01$ vs. untreated cells. RSF, Radix Sophorae Flavescentis; CTRL, control; Bcl-2, B cell lymphoma 2; Bax, apoptosis regulator BAC; FAS, apoptosis-mediating surface antigen FAS; FASL, Fas ligand.
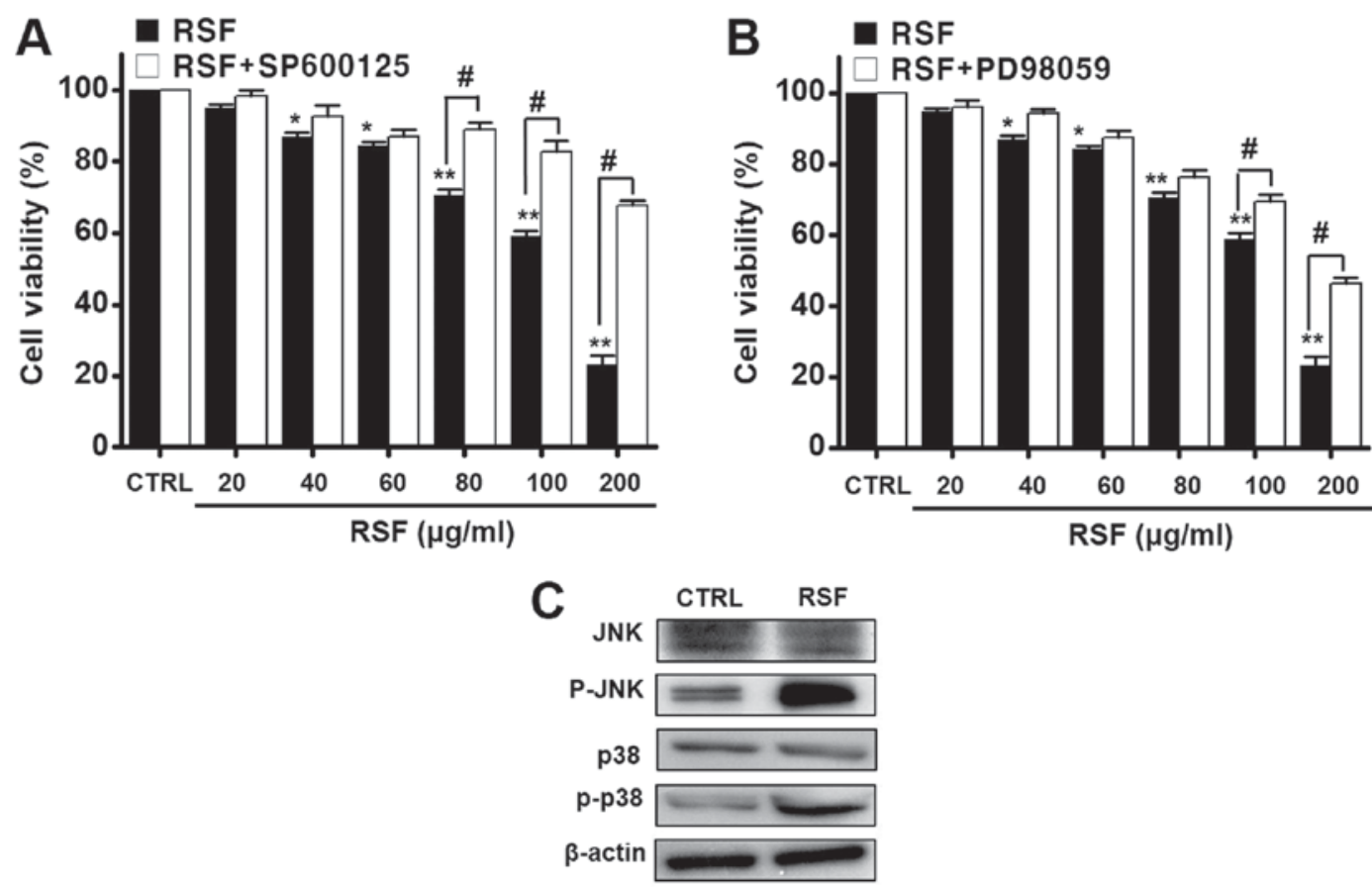

Figure 5. Effect of RSF on the MAPK pathway in AGS cells. Cell viability was determined in the presence of (A) SP600125 or (B) PD98059 by MTT assay. Cells were co-treated with the indicated concentrations of RSF (both at $10 \mu \mathrm{M}$ ) for $24 \mathrm{~h}$. (C) Expression of JNK, p-JNK, p38 MAPK and p-p38 MAPK proteins was determined by western blotting with $\beta$-actin as the control. Results are presented as the mean \pm standard error of the mean. ${ }^{*} \mathrm{P}<0.05$, ${ }^{* * *} \mathrm{P}<0.01$ vs. untreated cells; "P<0.05. RSF, Radix Sophorae Flavescentis; CTRL, control; JNK, c-Jun N-terminal kinase; MAPK, mitogen-activated protein kinase; p, phosphorylated.

Therefore, matrine or oxymatrine may be the major components of RSF induced AGS cell death. Matrine or oxymatrine may have anti-cancer effects and in future, they will be used as anti-cancer agents, especially in gastric cancer.
Apoptosis can be initiated via two signalling pathways: The extrinsic and intrinsic pathway $(30,31)$. The extrinsic pathway is initiated by extracellular signals such as, Fas ligand (FasL) (32). The intrinsic pathway, on the other hand is 
A

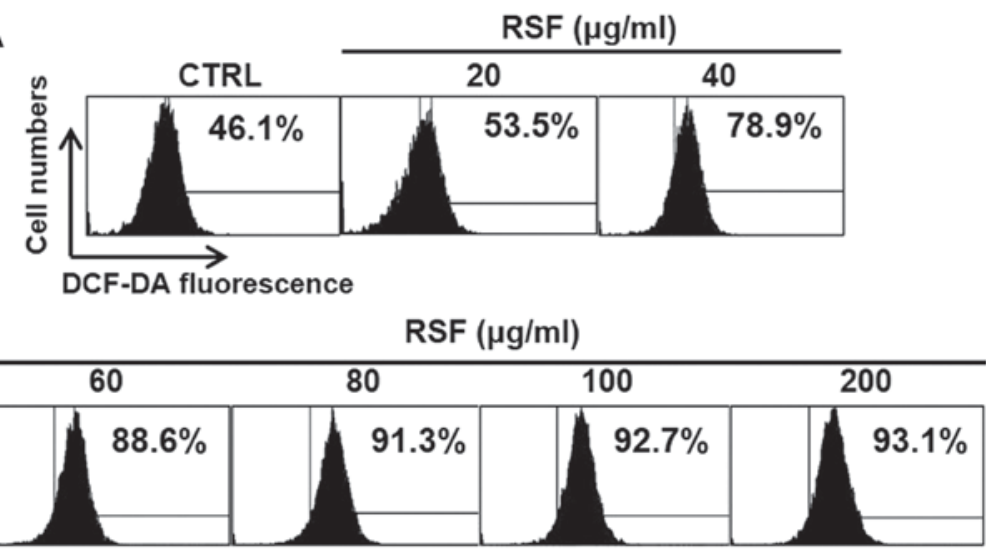

B

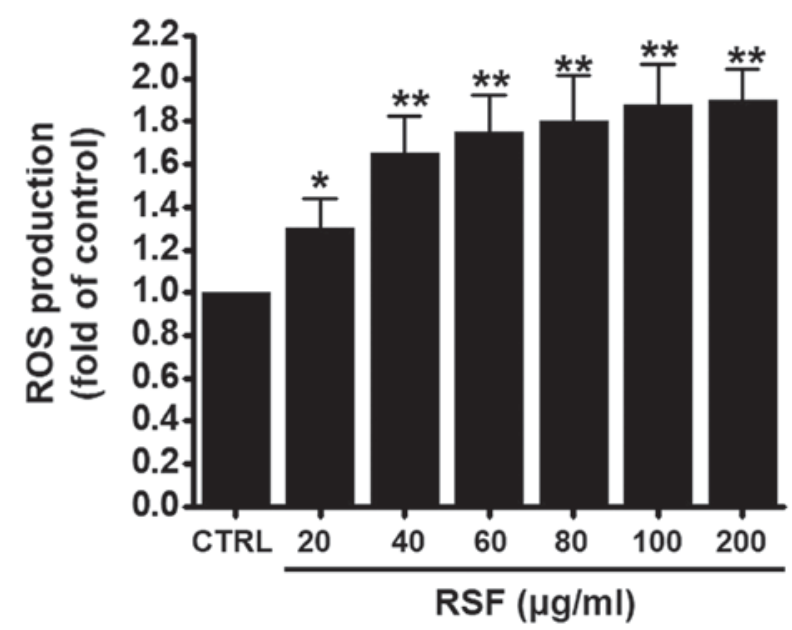

Figure 6. RSF enhances ROS accumulation in AGS cells. (A) Cells were stained with DCF-DA and intracellular ROS levels were measured. (B) Intracellular ROS was detected in AGS cells treated with the indicated concentrations of RSF for $24 \mathrm{~h}$. ROS levels are expressed as a percentage of those of untreated cells. Results are presented as the mean \pm standard error of the mean. ${ }^{*} \mathrm{P}<0.05,{ }^{* *} \mathrm{P}<0.01$ vs. untreated cells. RSF, Radix Sophorae Flavescentis; CTRL, control; ROS, reactive oxygen species.

regulated by $\mathrm{Bcl}-2$ family proteins (33). Caspases belong to a group of enzymes called cysteine proteases that are known to induce apoptotic processes (34). In our study, Bcl-2 expression was inhibited by RSF, while Bax expression was upregulated (Fig. 4A). Fas and FasL expression levels were up-regulated (Fig. 4B). Cell death is a complex biological phenomenon regulated by multiple cellular processes, including apoptosis and autophagy (35). Apoptosis and autophagy share common molecular pathways and also exhibit synergistic or antagonistic effects on each other during cell death (36-38). The relationship between apoptosis and autophagy is largely unknown in gastric cancer $(39,40)$. Therefore, to develop anti-cancer therapeutic agents, understanding the interactions between apoptosis and autophagy is vital.

The induction of apoptosis leads to characteristic cell changes and finally to death. These changes include blebbing, cell shrinkage, nuclear fragmentation, chromatin condensation, and chromosomal DNA fragmentation (30,31). Apoptosis involves a complex cascade of reactions regulated by specific proteases called caspases, and results in DNA degradation (34). Autophagy describes the fundamental catabolic mechanism during which cells degrade dysfunctional and unnecessary cellular components $(41,42)$. This process is driven by the action of lysosomes and promotes survival during starvation periods, as the cellular energy level can thus be maintained (42). In this study, RSF did not induce the autophagy (data not shown), but the apoptosis. Therefore, these results suggest that RSF may induce caspase-dependent AGS cell death, not lysosomal enzyme-dependent cell death.

Medicinal herbs and their derivatives are increasingly being used as a complementary treatment of cancer (41). Many clinical studies have highlighted the benefits of traditional herbal medicines on the quality of life of cancer patients $(43,44)$. Therefore, we propose that when combined with chemotherapy, herbal medicines could enhance the efficacy level and minimise toxic reactions.

Activated transient receptor potential melastatin 7 (TRPM7) channels contribute to a number of physiological and pathophysiological processes (45-47). TRPM7 is a member of the large TRP channel superfamily expressed in nearly every tissue and cell type (48). Human gastric adenocarcinoma cells express the TRPM7 channel, which is essential for cell survival and is a potential pharmacological target for the treatment of gastric cancer (49). Therefore, we plan to investigate the role of TRPM7 in RSF-treated gastric cancer cells in the future, which we believe is a new research area.

The signalling pathway of RSF-induced apoptosis in AGS cells can be summarised as follows. RSF promotes the 
expression of the pro-apoptotic factor Bax, but decreases the expression of the anti-apoptotic factor Bcl-2. These changes result in the release of cytochrome $\mathrm{c}$ in the cytosol. Cytochrome $\mathrm{c}$ activates the caspase- 3 cascade, which leads to cell death via the intrinsic apoptotic pathway. Another possible pathway is the extrinsic apoptotic pathway, which acts through the ROS-mediated JNK/p38 MAPK cascade. Therefore, we further propose that RSF-induced cell death acts via a ROS-mediated JNK/p38 MAPK signalling pathway that enhances the up-regulation of pro-apoptotic genes.

In conclusion, we have demonstrated that RSF inhibits proliferation of AGS cells, and extends the sub-G1 phase ratio. Additionally, RSF-induced apoptotic cell death is associated with $\mathrm{BCl}-2$ down-regulation and Bax up-regulation. RSF activates caspase-3 and mitogen-activated protein kinase (MAPK) but the C-Jun N-terminal kinase (JNK) inhibitors negate RSF-induced cell death. RSF also increases the generation of reactive oxygen species (ROS). Therefore, RSF may cause cell death via the intrinsic pathway in AGS human gastric cancer cells, and these findings indicate that RSF is a useful potential anticancer agent.

\section{Acknowledgements}

Not applicable.

\section{Funding}

The present study was supported by a Korean National Research Foundation Grant funded by the Korean Government (MSIP; grant no. 2014R1A5A2009936).

\section{Availability of data and materials}

The datasets used and/or analyzed during the current study are available from the corresponding author on reasonable request.

\section{Authors' contributions}

JSK and BJK designed the research. JSK, SJS, JNK, MJK, EYL, YTK and HK performed the experiments. JSK, JNK and BJK analyzed the data. JSK and BJK wrote the paper.

\section{Ethics approval and consent to participate}

Not applicable.

\section{Patient consent for publication}

Not applicable.

\section{Competing interests}

The authors declare that they have no competing interests.

\section{References}

1. Ferro A, Peleteiro B, Malvezzi M, Bosetti C, Bertuccio P, Levi F, Negri E, La Vecchia $C$ and Lunet N: Worldwide trends in gastric cancer mortality (1980-2011), with predictions to 2015, and incidence by subtype. Eur J Cancer 50: 1330-1344, 2014.
2. Jemal A, Bray F, Center MM, Ferlay J, Ward E and Forman D: Global cancer statistics. CA Cancer J Clin 61: 69-90, 2011.

3. Carcas LP: Gastric cancer review. J Carcinog 13: 14, 2014.

4. Boon HS, Olatunde F and Zick SM: Trends in complementary/alternative medicine use by breast cancer survivors: Comparing survey data from 1998 and 2005. BMC Womens Health 7: 4, 2007.

5. Li X, Yang G, Li X, Zhang Y, Yang J, Chang J, Sun X, Zhou X, Guo Y, Xu Y, et al: Traditional Chinese medicine in cancer care: A review of controlled clinical studies published in Chinese. PLoS One 8: e60338, 2013.

6. Yoder LH: Let's talk 'cancer prevention'. Medsurg Nurs 14: 195-198, 2005.

7. Ernst E: Complementary and alternative medicine (CAM) and cancer: The kind face of complementary medicine. Int J Surg 7: 499-500, 2009

8. Liu J, Zhu M, Shi R and Yang M: Radix Sophorae flavescentis for chronic hepatitis B: A systematic review of randomized trials. Am J Chin Med 31: 337-354, 2003

9. Xu GL, Yao L, Rao SY, Gong ZN, Zhang SQ and Yu SQ: Attenuation of acute lung injury in mice by oxymatrine is associated with inhibition of phosphorylated p38 mitogen activated protein kinase. J Ethnopharmacol 98: 177-183, 2005.

10. Yang X, Cai W, Yang Q, Lu Z, Li J and Yu J: Compound Radix Sophorae Flavescentis exerts antitumor effects by inhibiting the proliferation and inducing the apoptosis of esophageal carcinoma TE-8 cells. Oncol Lett 10: 2209-2213, 2015.

11. Drew AK, Bensoussan A, Whyte IM, Dawson AH, Zhu X and Myers SP: Chinese herbal medicine toxicology database monograph on Radix Sophorae Flavescentis, 'ku shen'. J Toxicol Clin Toxicol 40: 173-176, 2002.

12. Zhong J, Liu Z, Zhou X and Xu J: Synergic anti-pruritus mechanisms of action for the Radix Sophorae Flavescentis and fructus cnidii herbal pair. Molecules 22: pii: E1465, 2017.

13. Hwang GB, Lee JE, Nho CW, Lee BU, Lee SJ, Jung JH and Bae GN: Short-term effect of humid airflow on antimicrobial air filters using Sophora flavescens nanoparticles. Sci Total Environ 421-422: 273-279, 2012.

14. Jin JH, Kim JS, Kang SS, Son KH, Chang HW and Kim HP: Anti-inflammatory and anti-arthritic activity of total flavonoids of the roots of Sophora flavescens. J Ethnopharmacol 127: 589-595, 2010.

15. Wang Y, Han C, Fang X, Shi X, Feng A, He K, Zhang S and Sun X: Effect of kushen (Radix Sophorae Flavescentis) extract on laryngeal neoplasm Hep2 cells. J Tradit Chin Med 33: 218-222, 2013.

16. Wang Q, Xu J,Li X, Zhang D, Han Y and Zhang X: Comprehensive two-dimensional PC-3 prostate cancer cell membrane chromatography for screening anti-tumor components from Radix Sophorae Flavescentis. J Sep Sci 40: 2688-2693, 2017.

17. Nicoletti I, Migliorati G, Pagliacci MC, Grignani F and Riccardi C: A rapid and simple method for measuring thymocyte apoptosis by propidium iodide staining and flow cytometry. J Immunol Methods 139: 271-279, 1991

18. Wang BJ, Won SJ, Yu ZR and Su CL: Free radical scavenging and apoptotic effects of Cordyceps sinensis fractionated by supercritical carbon dioxide. Food Chem Toxicol 43: 543-552, 2005.

19. Zhao BG: Study on alkaloids of Sophora Alopecuroides. Yao Xue Xue Bao 15: 182-183, 1980.

20. Sun M, Han J, Duan J, Cui Y, Wang T, Zhang W, Liu W, Hong J, Yao M, Xiong S and Yan X: Novel antitumor activities of Kushen flavonoids in vitro and in vivo. Phytother Res 21: 269-277, 2007.

21. Sun M, Cao H, Sun L, Dong S, Bian Y, Han J, Zhang L, Ren S, $\mathrm{Hu}$ Y, Liu C, et al: Antitumor activities of kushen: Literature review. Evid Based Complement Alternat Med 2012: 373219, 2012.

22. Cheng H, Xia B, Zhang L, Zhou F, Zhang YX, Ye M, Hu ZG, Li J, Li J, Wang ZL, et al: Matrine improves 2,4,6-trinitrobenzene sulfonic acid-induced colitis in mice. Pharmacol Res 53: 202-208, 2006.

23. Li Y, Wang B, Zhou C and Bi Y: Matrine induces apoptosis in angiotensin II-stimulated hyperplasia of cardiac fibroblasts: Effects on Bcl-2/Bax expression and caspase-3 activation. Basic Clin Pharmacol Toxicol 101: 1-8, 2007.

24. Liu XS, Jiang J, Jiao XY, Wu YE and Lin JH: matrine induced apoptosis in leukemia U937 cells: Involvement of caspases activation and MAPK-independent pathways. Planta Med 72: 501-506, 2006.

25. Liu XY, Fang H, Yang ZG, Wang XY, Ruan LM, Fang DR, Ding YG, Wang YN, Zhang Y, Jiang XL and Chen HC: Matrine inhibits invasiveness and metastasis of human malignant melanoma cell line A375 in vitro. Int J Dermatol 47: 448-456, 2008. 
26. Jiang H, Hou C, Zhang S, Xie H, Zhou W, Jin Q, Cheng X, Qian R and Zhang X: Matrine upregulates the cell cycle protein E2F-1 and triggers apoptosis via the mitochondrial pathway in K562 cells. Eur J Pharmacol 559: 98-108, 2007.

27. Song MQ, Zhu JS, Chen JL, Wang L, Da W, Zhu L and Zhang WP: Synergistic effect of oxymatrine and angiogenesis inhibitor NM-3 on modulating apoptosis in human gastric cancer cells. World J Gastroenterol 13: 1788-1793, 2007.

28. Ling Q, Xu X, Wei X, Wang W, Zhou B, Wang B and Zheng S: Oxymatrine induces human pancreatic cancer PANC-1 cells apoptosis via regulating expression of $\mathrm{Bcl}-2$ and IAP families and releasing of cytochrome c. J Exp Clin Cancer Res 30: 66, 2011.

29. Zhang Y, Piao B, Zhang Y, Hua B, Hou W, Xu W, Qi X, Zhu X, Pei Y and Lin H: Oxymatrine diminishes the side population and inhibits the expression of $\beta$-catenin in MCF-7 breast cancer cells Med Oncol 28 (Suppl 1): S99-S107, 2011.

30. Thompson CB: Apoptosis in the pathogenesis and treatment of disease. Science 267: 1456-1462, 1995.

31. Adams JM and Cory S: The Bcl-2 apoptotic switch in cancer development and therapy. Oncogene 26: 1324-1337, 2007.

32. Wajant H: The Fas signaling pathway: More than a paradigm. Science 296: 1635-1636, 2002.

33. Cory S and Adams JM: The Bcl2 family: Regulators of the cellular life-or-death switch. Nat Rev Cancer 2: 647-656, 2002.

34. Earnshaw WC, Martins LM and Kaufmann SH: Mammalian caspases: Structure, activation, substrates, and functions during apoptosis. Annu Rev Biochem 68: 383-424, 1999.

35. Lockshin RA and Zakeri Z: Apoptosis, autophagy, and more. Int J Biochem Cell Biol 36: 2405-2419, 2004.

36. Thorburn A: Apoptosis and autophagy: Regulatory connections between two supposedly different processes. Apoptosis 13: 1-9, 2008.

37. Maiuri MC, Zalckvar E, Kimchi A and Kroemer G: Self-eating and self-killing: Crosstalk between autophagy and apoptosis. Nat Rev Mol Cell Biol 8: 741-752, 2007.

38. Kim SH, Park EJ, Lee CR, Chun JN, Cho NH, Kim IG, Lee S, Kim TW, Park HH, So I and Jeon JH: Geraniol induces cooperative interaction of apoptosis and autophagy to elicit cell death in PC-3 prostate cancer cells. Int J Oncol 40: 1683-1690, 2012.
39. Bento CF, Renna M, Ghislat G, Puri C, Ashkenazi A, Vicinanza M, Menzies FM and Rubinsztein DC: Mammalian autophagy: How does it work? Annu Rev Biochem 85: 685-713, 2016.

40. Sun T, Liu H and Ming L: Multiple roles of autophagy in the sorafenib resistance of hepatocellular carcinoma. Cell Physiol Biochem 44: 716-727, 2017.

41. Huang F, Wang BR and Wang YG: Role of autophagy in tumorigenesis, metastasis, targeted therapy and drug resistance of hepatocellular carcinoma. World J Gastroenterol 24: 4643-4651, 2018.

42. Wilde L, Tanson K, Curry J and Martinez-Outschoorn U: Autophagy in cancer: A complex relationship. Biochem J 475: 1939-1954, 2018

43. Yin SY, Wei WC, Jian FY and Yang NS: Therapeutic applications of herbal medicines for cancer patients. Evid Based Complement Alternat Med 2013: 302426, 2013.

44. Li HC, Xia ZH, Chen YF, Yang F, Feng W, Cai H, Mei Y, Jiang YM, Xu K and Feng DX: Cantharidin inhibits the growth of triple-negative breast cancer cells by suppressing autophagy and inducing apoptosis in vitro and in vivo. Cell Physiol Biochem 43: 1829-1840, 2017

45. Jin J, Desai BN, Navarro B, Donovan A, Andrews NC and Clapham DE: Deletion of Trpm7 disrupts embryonic development and thymopoiesis without altering $\mathrm{Mg} 2+$ homeostasis. Science 322: 756-760, 2008.

46. Jiang J, Li MH, Inoue K, Chu XP, Seeds J and Xiong ZG: Transient receptor potential melastatin 7-like current in human head and neck carcinoma cells: Role in cell proliferation. Cancer Res 67: 10929-10938, 2007.

47. Schmitz C, Perraud AL, Johnson CO, Inabe K, Smith MK, Penner R, Kurosaki T, Fleig A and Scharenberg AM: Regulation of vertebrate cellular Mg2+ homeostasis by TRPM7. Cell 114: 191-200, 2003.

48. Clapham DE: TRP channels as cellular sensors. Nature 426: 517-524, 2003

49. Kim BJ, Park EJ, Lee JH, Jeon JH, Kim SJ and So I: Suppression of transient receptor potential melastatin 7 channel induces cell death in gastric cancer. Cancer Sci 99: 2502-2509, 2008. 